\title{
Double-Blind, Crossover, Placebo-Controlled Clinical Trial with Clobetasol Propionate in Desquamative Gingivitis
}

\author{
Ana Carolina Fragoso MOTTA ${ }^{1,2}$ \\ Carina DOMANESCHI ${ }^{1}$ \\ Marilena Chinali KOMESU ${ }^{2}$ \\ Cacilda da Silva SOUZA ${ }^{3}$ \\ Valéria $\mathrm{AOKI}^{4}$ \\ Dante Antonio MIGLIARI ${ }^{1}$
}

\author{
${ }^{1}$ Department of Oral Diagnosis, Dental School, University of São Paulo, São Paulo, SP, Brazil \\ ${ }^{2}$ Department of Morphology, Stomatology and Physiology, Ribeirão Preto Dental School, \\ University of São Paulo, Ribeirão Preto, SP, Brazil \\ ${ }^{3}$ Department of Internal Medicine, Medical School of Ribeirão Preto, University of São Paulo, Ribeirão Preto, SP, Brazil \\ ${ }^{4}$ Department of Dermatology, Medical School, University of São Paulo, São Paulo, SP, Brazil
}

\begin{abstract}
The aim of this study was to evaluate the efficacy of a $0.05 \%$ clobetasol propionate ointment administered in trays to 22 patients with desquamative gingivitis in a double-blind, crossover, placebo-controlled trial. Patients received container number 1 and were instructed to apply the ointment 3 times a day for 2 weeks, and to reduce the application to once a day in the third week. Next, the patients were then instructed to discontinue the treatment for 2 weeks, and were then given container 2, used in the same way and for the same length of time as container 1. Regarding signs, 17 patients presented some improvement, while 5 experienced worsening with clobetasol propionate. With the placebo, 14 patients presented some improvement, and 8 patients presented worsening. For symptoms, there was complete improvement in 2 patients, partial improvement in 12, no response in 7, and worsening in 1 with clobetasol propionate. With the placebo, there was partial improvement in 8 patients, no response in 12 and worsening in 2 . No statistically significant difference was found between clobetasol and placebo $(p>0.05)$. Within the period designed to treat the gingival lesions of the patients, clobetasol propionate did not significantly outperform the placebo.
\end{abstract}

Key Words: immunobullous disease, oral mucosa, clobetasol propionate.

\section{INTRODUCTION}

Management of the gingival manifestations, clinically known as desquamative gingivitis, of autoimmune and inflammatory mucocutaneous diseases represents a great challenge to oral medicine clinicians, since most of these diseases are of a chronic nature (1-3). While systemic therapy may be required for the underlying disease, especially in cases associated with pemphigus vulgaris (PV), topical corticosteroids are often the mainstay for the treatment of localized gingival lesions (4-8). Clobetasol propionate has yielded good results with minimal side effects when properly used (5,9-11). Some studies have reported good outcomes for patients with oral lesions treated with clobetasol propionate in a mouthwash (3), and in an ointment with or without an adherent vehicle (7-12). However, it may be difficult to apply the corticosteroid to the entire lesional surface in patients with extensive gingival lesions. It has also been reported that the grainy texture of the paste with adherent vehicle is generally disliked, often affecting patient compliance. In addition, physiological mouth movements can displace the corticosteroid from its initial location, precluding good control of the contact 
time between the corticosteroid and the lesion $(6,7,12)$. The use of a tray may provide a solution to this problem because it restrains the ointment and provides an occlusive contact between the corticosteroid and the lesions $(12,13)$. The present double-blind, crossover, placebocontrolled study was carried out to evaluate the efficacy of clobetasol propionate administered in trays for the treatment of gingival manifestations of autoimmune and inflammatory mucocutaneous diseases.

\section{MATERIAL AND METHODS}

\section{Patients}

Twenty-two patients (17 women and 5 men; mean age $=50.6 \pm 16.38$ years; range $25-78$ years) with chronic and symptomatic gingival lesions caused by autoimmune and inflammatory mucocutaneous diseases participated in the study. The patients were divided into 2 groups: group 1 consisted of 5 patients, all women, mean age $48.2 \pm 8.13$ years (range $38-58$ years), treated systemically with prednisone and/or azathioprine for at least 6 months for control of their mucocutaneous diseases. All patients in this group presented PV; the duration of the disease was $8.2 \pm 3.42$ years (range $4-11$ years). Group 2 consisted of 17 patients, 12 women, 5 men, mean age $51.4 \pm 18.25$ years (range $25-78$ years), not under systemic treatment. In this group, 3 patients presented PV, 5 presented mucous membrane pemphigoid (MMP), and 9 had oral lichen planus (OLP); the duration of these diseases, taken together, was $5.6 \pm$ 4.04 years, range $1-15$ years. The characteristics of the patients are shown in Table 1.

The diagnosis of these diseases was made based on medical history and clinical examination, together with histopathologic (light microscopy - hematoxylin and eosin) and direct immunofluorescence findings of a biopsy specimen taken from the perilesional gingival mucosa. The clinical criteria for inclusion in this study were: presence of erythema, atrophy, vesicobullous areas, erosions, ulcerations and desquamative lesions, in multiple associations or not. Subjects were excluded if they presented disseminated mucocutaneous diseases or exacerbation of their diseases during the study period, or if they were taking any drugs capable of inducing lichenoid reactions. Blood pressure, glycemia, complete blood counts, and presence of candidosis were recorded at the start and at the end of the each protocol phase. Oral candidosis was diagnosed by evidence of fungal hyphae detected by exfoliative cytology of the gingival mucosa (direct exam with $10 \% \mathrm{KOH}$ and periodic acid Schiff staining). The trial was approved by the local Research Ethics Committee and all subjects gave written informed consent to participate.

\section{Drug}

The drug under study was a $0.05 \%$ clobetasol propionate ointment ( $0.5 \mathrm{mg}$ of clobetasol 17-propionate). The efficacy of this corticosteroid was compared to that of a placebo (hydroxylethyl cellulose) with the same physical characteristics as the corticosteroid (odorless, tasteless, and colorless). The ointments were prepared in equal containers of $30 \mathrm{~g}$ (containers number 1 and 2). The containers with randomization codes were obtained by Galderma Brasil Ltda, São Paulo, SP, Brazil. The code was not broken until completion of the crossover study.

\section{Study Design}

After an initial periodontal treatment, a topical application of ointments was instituted using trays of

Table 1. General characteristics of the patients $(n=22)$.

\begin{tabular}{|c|c|c|c|c|c|c|c|}
\hline \multirow{2}{*}{ Patients } & \multicolumn{2}{|c|}{ Gender } & \multirow{2}{*}{ Age (yrs) } & \multicolumn{3}{|c|}{ Mucocutaneous diseases } & \multirow{2}{*}{$\begin{array}{l}\text { Duration of the } \\
\text { diseases (yrs) }\end{array}$} \\
\hline & Male & Female & & PV & MMP & OLP & \\
\hline Group $1(\mathrm{n}=5)$ & 0 & $5(22.7)$ & $38-58(48.2 \pm 8.13)$ & $5(22.7)$ & 0 & 0 & $4-11(8.2 \pm 3.42)$ \\
\hline Group $2(\mathrm{n}=17)$ & $5(22.7)$ & $12(54.6)$ & $25-78(51.4 \pm 18.25)$ & $3(13.6)$ & $5(22.7)$ & $9(40.9)$ & $1-15(5.6 \pm 4.04)$ \\
\hline Total $(n=22)$ & $5(22.7)$ & $17(77.3)$ & $25-78(50.6 \pm 16.38)$ & $8(36.4)$ & $5(22.7)$ & $9(40.9)$ & $1-15(6.2 \pm 3.98)$ \\
\hline
\end{tabular}

$\mathrm{PV}=$ pemphigus vulgaris; $\mathrm{MMP}=$ mucous membrane pemphigoid; $\mathrm{OLP}=$ oral lichen planus. Data are expressed as 'number of patients $(\%)$ '. 
silicone rubber made on cast impressions. The patients received container number 1 and were instructed to apply the ointment with the tray for 20 min, 3 times daily (after breakfast, after lunch and after dinner), for 2 weeks. The frequency of use of ointment was reduced in the third week to once a day on alternate days. The patients were then instructed to discontinue the treatment for 2 weeks (washout period), and were given container number 2, to be used in the same way and at the same frequency and duration as container 1 .

\section{Clinical Response}

Patients were examined before the trial and then at 2-week intervals throughout the trial. The patients' clinical evaluation was recorded at each visit on their charts, which consisted of a diagram of the gingival mucosa with 6 sites for tooth where the areas with lesions were marked. For signs, the response to therapy was defined as follows according to the percent of remission: complete (100\%), excellent ( $75 \%$ to $99 \%)$, good $(50 \%$ to $74 \%$ ), poor ( $1 \%$ to $49 \%$ ), no response, and worsened. Remission of symptoms was characterized as complete (no symptoms), partial, no response, and worsened. At every visit, the patients were also examined for the presence of side effects. Data were analyzed by Fisher's exact test. Significance was set at $\mathrm{p}<0.05$.

\section{RESULTS}

Data on the clinical response of patients in each phase of this study are summarized in Tables 2 and 3 . With respect to the evaluation of signs, 17 patients (77.2\%) presented some improvement (Fig. 1), while 5 (22.7\%) presented worsening with the use of clobetasol propionate. With the placebo, 14 patients $(63.6 \%)$ presented some improvement, while 8 patients $(36.4 \%)$ had worsening of signs (Table 2). For symptoms, complete improvement was observed in 2 patients $(9.1 \%)$, partial improvement in 12 (54.5\%), no response in 7 (31.8\%) and worsening in 1 during the clobetasol phase. During the placebo phase, 8 patients $(36.4 \%)$ had partial improvement, $12(54.5 \%)$ no response and $2(9.1 \%)$ showed worsening (Table 3 ).

Despite a tendency of the patients to respond slightly better to clobetasol in terms of improvement of signs and symptoms of their gingival lesions, no statistically significant difference was found between the results obtained with clobetasol propionate and the placebo ( $p>0.05$ ). With respect to side effects, only 2 patients $(9.1 \%)$ developed candidosis during the use of clobetasol propionate. These 2 patients were additionally treated with an antifungal (Nistatin) in oral suspension for 3 weeks, and a further retest for Candida $s p$ was negative. No other side effects were observed in the patients of this study.

\section{DISCUSSION}

By comparing the severity of lesions at baseline with their outcome at the end of the trial, it was found that patients in the clobetasol phase showed a slightly better improvement of clinical signs and symptoms compared with those in the placebo phase, although the
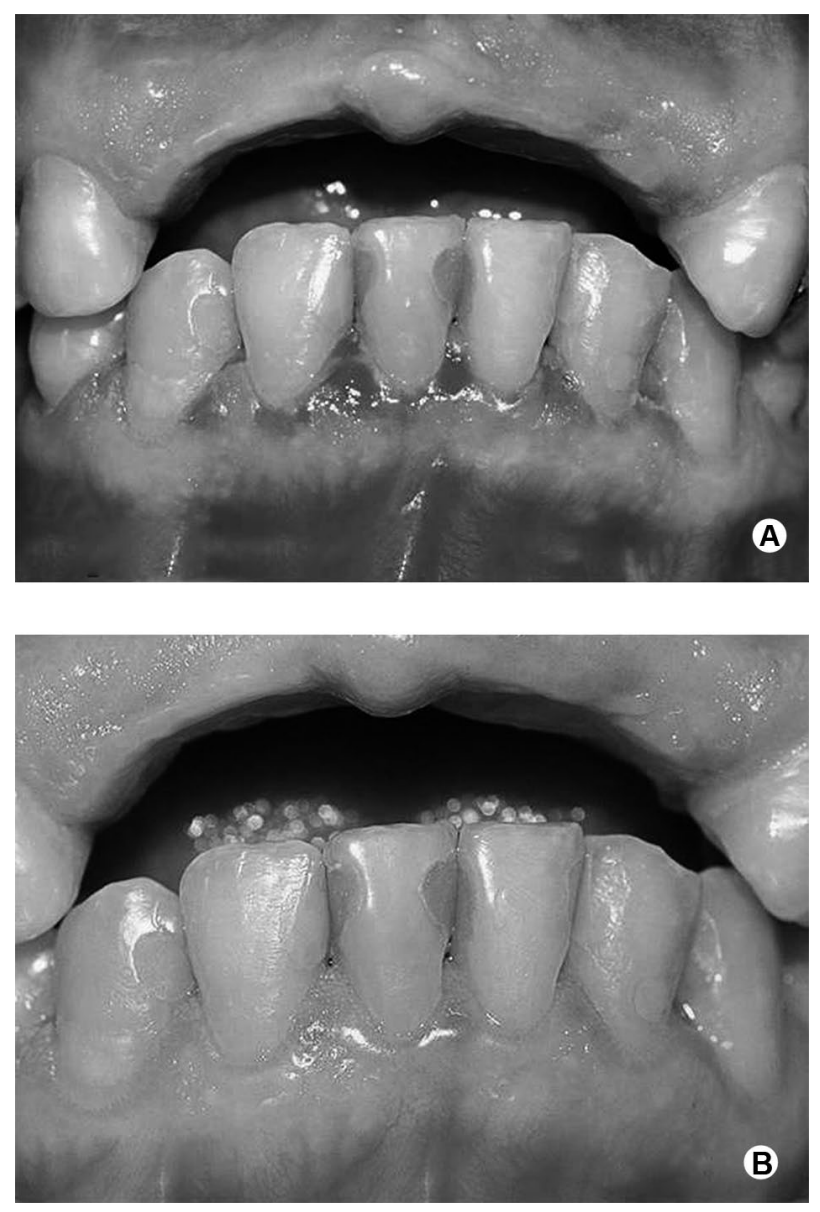

Figure 1. Clinical photographs of patient illustrating the response to the treatment $. \mathrm{A}=$ Erosive lesions in the marginal gingiva of a patient with pemphigus vulgaris. $\mathrm{B}=$ Partial remission following 15 days of treatment with clobetasol propionate. 
Table 2. Clinical response of signs of patients treated with clobetasol propionate and placebo.

\begin{tabular}{|c|c|c|c|c|c|c|c|}
\hline \multirow{2}{*}{ Patients } & \multicolumn{7}{|c|}{ Response of signs } \\
\hline & Complete & Excellent & Good & Poor & No response & Worse & Total \\
\hline \multicolumn{8}{|l|}{ Group $1(\mathrm{n}=5)$} \\
\hline Clobetasol & 0 & 0 & 0 & $4(80)$ & 0 & $1(20)$ & $5(100)$ \\
\hline Placebo & 0 & 0 & 0 & $4(80)$ & 0 & $1(20)$ & $5(100)$ \\
\hline $\mathrm{p}$ values & 1.00 & 1.00 & 1.00 & 0.65 & 1.00 & 0.75 & --- \\
\hline \multicolumn{8}{|l|}{ Group $2(\mathrm{n}=17)$} \\
\hline Clobetasol & 0 & $1(5.9)$ & $2(11.8)$ & $10(58.8)$ & 0 & $4(23.5)$ & $17(100)$ \\
\hline Placebo & 0 & $2(11.8)$ & 0 & $8(47)$ & 0 & $7(41.2)$ & $17(100)$ \\
\hline $\mathrm{p}$ values & 1.00 & 0.50 & 0.24 & 0.36 & 1.00 & 0.23 & --- \\
\hline \multicolumn{8}{|c|}{ All patients $(\mathrm{n}=22)$} \\
\hline Clobetasol & 0 & $1(4.5)$ & $2(9.1)$ & $14(63.6)$ & 0 & $5(22.7)$ & $22(100)^{*}$ \\
\hline Placebo & 0 & $2(9.1)$ & 0 & $12(54.5)$ & 0 & $8(36.4)$ & $22(100)^{*}$ \\
\hline $\mathrm{p}$ values & 1 & 0.49 & 0.24 & 0.37 & 1.00 & 0.25 & --- \\
\hline
\end{tabular}

Data are expressed as 'number of patients (\%)'; * ns - nonsignificant (Fisher's exact test; $\mathrm{p}>0.05$ ).

Table 3. Clinical response of symptoms of patients treated with clobetasol propionate and placebo.

\begin{tabular}{|c|c|c|c|c|c|}
\hline \multirow{2}{*}{ Patients } & \multicolumn{5}{|c|}{ Response of symptoms } \\
\hline & Complete & Partial & No response & Worse & Total \\
\hline \multicolumn{6}{|l|}{ Group $1(n=5)$} \\
\hline Clobetasol & 0 & $3(60)$ & $1(20)$ & $1(20)$ & $5(100)$ \\
\hline Placebo & 0 & $1(20)$ & $4(80)$ & 0 & $5(100)$ \\
\hline $\mathrm{p}$ values & 1.00 & 0.26 & 0.10 & 0.50 & --- \\
\hline \multicolumn{6}{|l|}{ Group $2(n=17)$} \\
\hline Clobetasol & $2(11.8)$ & $9(52.9)$ & $6(35.2)$ & 0 & $17(100)$ \\
\hline Placebo & 0 & $7(41.2)$ & $8(47)$ & $2(11.8)$ & $17(100)$ \\
\hline $\mathrm{p}$ values & 0.24 & 0.36 & 0.36 & 0.24 & --- \\
\hline \multicolumn{6}{|l|}{ All patients $(n=22)$} \\
\hline Clobetasol & $2(9.1)$ & $12(54.5)$ & $7(31.8)$ & $1(4.5)$ & $22(100)^{*}$ \\
\hline Placebo & 0 & $8(36.4)$ & $12(54.5)$ & $2(9.1)$ & $22(100)^{*}$ \\
\hline $\mathrm{p}$ values & 0.24 & 0.18 & 0.11 & 0.49 & --- \\
\hline
\end{tabular}

Data are expressed as 'number of patients (\%)'; * ns - nonsignificant (Fisher's exact test; $\mathrm{p}>0.05$ ). 
difference did not reach statistical significance $(\mathrm{p}>0.05)$. The failure of the corticosteroid to significantly outperform the placebo indicates that its vasoconstrictive, anti-inflammatory and immunosuppressive properties are not sufficient to suppress the immunologic and inflammatory mechanism involved in the development of the studied lesions. That both clobetasol propionate and the placebo ointment proved to be effective to some degree could be due to a protective and lubricating function of the ointment in conjunction with the use of trays. The occlusion produced by use of trays can have favored the protection of gingival tissues against functional movements of mouth.

Some double-blind studies showed the safety of topical clobetasol propionate in the treatment of oral vesiculo-erosive lesions $(5,6,9,10,14)$. Clobetasol in orabase paste administered in trays 3 times daily around 2 weeks of treatment provided good outcomes in patients with severe erosive gingival lesions (11-13). On the other hand, clobetasol ointment used for 4 weeks in DG treatment had previously been found to be significantly less effective when it was compared with other drugs, such as tacrolimus (15).

It has been recognized that either systemic or topical corticotherapy may bring about serious side effects, such as increased susceptibility to infections, hypertension, hyperglycemia, fluid retention, and adrenal cortex suppression $(1,6,16,17)$. With regard to topical therapy, the risk of side effects is increased when a high-potency corticosteroid is used in combination with occlusive techniques (17). Although only one study (3) has reported significant side effects with the use of topical high-potency corticosteroids in ulcerative and/or erosive oral lesions, there is a consensus among authors that patients under this type of treatment should be monitored carefully $(12,16,17)$. The patients applied the corticosteroid to their gingival lesions for a period of 3 weeks. This length of time was sufficient to evaluate side effects, since some studies have indicated that adrenal suppression may occur as early as $24 \mathrm{~h}$ after initiating topical corticotherapy when used on the skin $(16,18,19)$. The most common side effect of topical corticotherapy is candidosis $(17,20)$. In the present study, only 2 patients $(11.8 \%)$ developed candidosis after the use of clobetasol propionate. These patients were treated with a topical antifungal agent without interrupting the use of clobetasol. No other side effect was observed in the patients under study.
Topical corticosteroids, used as described in this paper, are usually safe and can be of some efficacy as adjunct therapy in combination with systemic treatment in patients with oral and skin lesions, or in the treatment of patients with gingival lesions alone. Although some of our patients did not show improvement of their gingival lesions while using clobetasol propionate, this may have been due to the limited sample size and the relatively short period of treatment. However, this shorter period does reduce the risk of side effects. A risk/benefit analysis should be undertaken when considering an increase in the dosage of any medication.

\section{RESUMO}

O objetivo deste estudo foi avaliar a eficácia do propionato de clobetasol a $0,05 \%$ administrada com moldeiras em 22 pacientes com gengivite descamativa por meio de estudo duplo-cego, cruzado, placebo-controlado. Pacientes receberam bisnaga número 1 e foram instruídos a aplicar a pomada 3 vezes ao dia por um período de 2 semanas, e reduzir a aplicação para 1 vez ao dia na terceira semana. Os pacientes foram instruídos a suspender o tratamento por 2 semanas, e então receberam a bisnaga 2, usando-a da mesma maneira que o container 1. Com relação aos sinais, 17 pacientes apresentaram alguma melhora, enquanto 5 apresentaram piora com o propionato de clobetasol. Com o uso do placebo, 14 pacientes apresentaram alguma melhora, e 8 pacientes apresentaram piora do seu quadro clínico. Com relação aos sintomas, houve completa melhora em 2 pacientes, melhora parcial em 12, ausência de resposta em 7, e piora em 1 pacientes durante o uso do propionato de clobetasol. Com o uso do placebo, houve melhora parcial em 8 pacientes, ausência de resposta em 12 e piora dos sintomas em 2 pacientes. Não foi verificada diferença estatisticamente significante em nenhum dos parâmetros entre o uso do clobetasol e placebo; $p>0,05$. Baseado no protocolo utilizado neste grupo de pacientes, o propionato de clobetasol não demonstrou efetividade significante quando comparado ao placebo.

\section{ACKNOWLEDGEMENTS}

The Dr. Ana Carolina F. Motta was supported by a scholarship from the Coordination for the Improvement of Graduated Personnel. The authors acknowledge the support of Galderma Brazil Ltda. for the production of the ointments and randomization.

\section{REFERENCES}

1. Lo Russo L, Fedele S, Guiglia R, Ciavarella D, Lo Muzio L, Gallo $\mathrm{P}$, et al.. Diagnostic pathways and clinical significance of desquamative gingivitis. J Periodontol 2008;79:4-24.

2. Laskaris G, Sklavounou A, Stratigos J. Bullous pemphigoid, cicatricial pemphigoid, and pemphigus vulgaris: a comparative clinical survey of 278 cases. Oral Surg Oral Med Oral Pathol 1982;54:656662. 
3. Gonzalez-Moles MA, Morales P, Rodríguez-Archilla A, Isabel IR, Gonzalez-Moles S. Treatment of severe chronic oral erosive lesions with clobetasol propionate in aqueous solution. Oral Surg Oral Med Oral Pathol Oral Radiol Endod 2002;93:264-270.

4. Endo H, Rees TD, Hallmon WW, Kuyama K, Nakadai M, Kato $\mathrm{T}$, et al. Disease progression from mucosal to mucocutaneous involvement in a patient with desquamative gingivitis associated with pemphigus vulgaris. J Periodontol 2008;79:369-375.

5. Lo Muzio L, della Valle A, Mignogna MD, Pannone G, Bucci P, Bucci E, et al.. The treatment of oral aphthous ulceration or erosive lichen planus with topical clobetasol propionate in three preparations: a clinical and pilot study on 54 patients. J Oral Pathol Med 2001;30:611-617.

6. Lozada-Nur F, Huang MZ. Open preliminary clinical trial of clobetasol propionate in adhesive paste for treatment of chronic oral vesiculoerosive diseases. Oral Surg Oral Med Oral Pathol 1991;71:283-287.

7. Lozada-Nur F, Miranda C, Maliksi R. Double-bind clinical trial of $0.05 \%$ clobetasol propionate ointment in orabase and $0.05 \%$ fluocinonide ointment in orabase in the treatment of patients with oral vesiculoerosive diseases. Oral Surg Oral Med Oral Pathol 1994; 77:598-604.

8. Gonzalez-Moles MA, Scully C. Vesiculo-erosive oral mucosal disease - management with topical corticosteroids: (1) Fundamental principles and specific agents available. J Dent Res 2005;84:294301.

9. Conrotto D, Carbone M, Carrozzo M, Arduino P, Broccoletti R, Pentenero M, et al.. Cyclosporin vs. Clobetasol in the topical management of atrophic and erosive oral lichen planus: a double-blind, randomized controlled trial. Br J Dermatol 2006;154:139-145.

10. Dumas V, Roujeau JC, Wolkenstein P, Revuz J, Cosnes A. The treatment of mild pemphigus vulgaris and pemphigus foliaceus with a topical corticosteroid. Br J Dermatol 1999;140:1127-1129.

11. Guiglia R, Di Liberto C, Pizzo G, Picone L, Lo Muzio L, Gallo PD, et al.. A combined treatment regimen for desquamative gingivitis in patients with oral lichen planus. J Oral Pathol Med 2007;36:110116.
12. Gonzalez-Moles MA, Ruiz-Avila I, Rodriguez-Archilla A, Morales-Garcia P, Mesa-Aguado F, Bascones-Martinez A, et al.. Treatment of severe erosive gingival lesions by topical application of clobetasol propionate in custom trays. Oral Surg Oral Pathol Oral Radiol Endod 2003;95:688-692.

13. Motta ACF, Komesu MC, Grisi MFM, Souza CS, Roselino AMF, Migliari DA. Topical corticosteroid for the treatment of gingival manifestations of vesicobullous autoimmune diseases. An Bras Dermatol 2006,81:283-285.

14. Carbone M, Conrotto D, Carrozzo M, Broccoletti R, Gandolfo S, Scully C. Topical corticosteroid in association with miconazole and chlorhexidine in the long-term management of atrophicerosive oral lichen planus: a placebo-controlled and comparative study between clobetasol and fluocinonide. Oral Dis 1999;5:4449.

15. Corrocher G, Di Lorenzo G, Mansueto P, Martinelli N, EspositoPellitteri M, Gelio S, et al.. Comparison of topical tacrolimus $0.1 \%$ in pectin ointment with clobetasol $0.5 \%$ ointment in adult with moderate to severe desquamative gingivitis: a week, randomized, double-blind clinical trial. Clin Ther 2006;28:1296-1302.

16. Plemons JM, Rees TD, Zachariah NY. Absorption of a topical steroid and evaluation of adrenal suppression in patients with erosive lichen planus. Oral Surg Oral Med Oral Pathol 1990;69:688-693.

17. Voûte AB, Schulten EA, Langendijk PN, Kostense PJ, van der Waal I. Fluocinonide in an adhesive base for treatment of oral lichen planus. A double-blind, placebo-controlled clinical study. Oral Surg Oral Med Oral Pathol 1993;75:181-185.

18. Kirketerp M. Systemic effects of local treatment with fluocinolone acetonide applied under a plastic film. Acta Dermato-Venereol 1964;44:54-58.

19. Mckenzie AW, Stoughton RB. Method for comparing percutaneous absorption of steroids Arch Derm 1962;86:608.

20. Scully C, Beyli M, Ferreiro MC, Ficarra G, Gill Y, Griffiths M, et al.. Update on oral lichen planus: etiopathogenesis and management. Crit Rev Oral Biol Med 1998;9:86-122.

Accepted August 11, 2009 